\title{
Progressive Fracture of Fiber Composites
}

Thomas B. Irvine and Carol A. Ginty Lewis Research Center Cleveland, Ohio

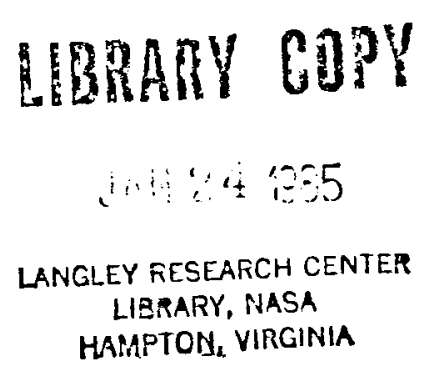

Prepared for the

Ninth Annual Mechanics of Composites Review sponsored by Air Force Wright Aeronautical Laboratories Dayton, Ohio, October 24-26, 1983

\section{N/Sก}


CONTENTS

SUMMARY . . . . . . . . . . . . . . . . . . . . . . . . . . . . . . 1

INTRODUCTION . . . . . . . . . . . . . . . . . . . . . . . . . . . . . 1

SPECIMEN PREPARATION . . . . . . . . . . . . . . . . . . . . . . . . 2

TESTING PROCEDURES . . . . . . . . . . . . . . . . . . . . . . . . . 2

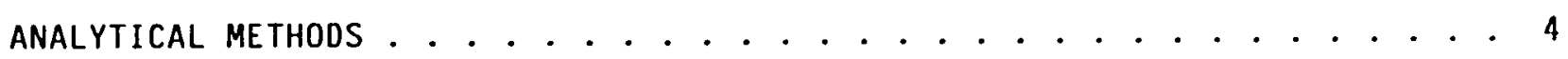

EXPERIMENTAL RESULTS . . . . . . . . . . . . . . . . . . . . . . . 4

SOLID SPECIMENS . . . . . . . . . . . . . . . . . . . . . . . . . . 5

NOTCHED SPECIMENS . . . . . . . . . . . . . . . . . . . . . . 5

ANALYTICAL RESULTS . . . . . . . . . . . . . . . . . . . . . . . 6

COMPARISON OF EXPERIMENTAL AND ANALYTICAL RESULTS . . . . . . . . . . . . . . . 7 LAMINATE STRENGTH . . . . . . . . . . . . . . . . . . . . . . . . 7 DEFECT GROWTH PATTERNS AND FAILURE MODES . . . . . . . . . . . . . . . . . . 8 GENERAL REMARKS/DEFINITIONS . . . . . . . . . . . . . . . . . . . . . . 9 SUMMARY OF RESULTS . . . . . . . . . . . . . . . . . . . . . . . . . 9 REFERENCES ............................... . . 10 
. 


\title{
PROGRESSIVE FRACTURE OF FIBER COMPOSITES
}

\author{
Thomas B. Irvine and Carol A. Ginty \\ National Aeronautics and Space Administration \\ Lewis Research Center \\ Cleveland, Ohio 44135
}

\section{SUMMARY}

Refined models and procedures are described for determining progressive composite fracture in graphite/epoxy angleplied laminates. Unique Lewis Research Center capabilities are utilized including the Real-Time Ultrasonic C-Scan (RUSCAN) experimental facility and the Composite Durability Structural Analysis (CODSTRAN) computer code. CODSTRAN is used to predict the fracture progression based on composite mechanics, finite element stress analysis, and fracture criteria modules. The RUSCAN facility, CODSTRAN computer code, and scanning electron microscope are used to determine durability and identify fallure mechanisms in graphite/epoxy composites. Results indicate that RUSCAN/ CODSTRAN is an effective method of studying progressive fracture of composites.

\section{INTRODUCTION}

The evaluation of composite durability and structural reliability is dependent upon having the capability to characterize defects and subsequent defect growth to fracture. Having this capability involves techniques and methods for determining combined stress states in composite laminates and the subsequent application of failure criteria. The objective of this study is to develop and refine models and procedures for determining progressive composite fracture including characterization of crack propagation and fallure mechanisms in graphite/epoxy angleplied laminates.

Unique Lewis Research Center capabilities utilized in this study include the Composite Durability Structural Analysis (CODSTRAN) computer code and the Real-Time Uitrasonic C-Scan (RUSCAN) experimental facility. The CODSTRAN computer code is an upward integrated mechanistic method for predicting durability and defect growth in composites. The program incorporates composite mechanics, laminate theory, structural analysis (finite element), and fracture criteria modules. The RUSCAN experimental facility is a nondestructive ultrasonic C-Scan testing apparatus which can scan a specimen or structure under an applied load for defects and damage. These two capabilities, along with postmortem analysis by scanning electron microscopy, are used to characterize progressive fracture of composites.

A series of 4-ply angleplied graphite/epoxy laminates were fabricated using fiberite $1034 \mathrm{E}$ prepreg (934 resin matrix system impregnated with Thorne) 300 graphite fibers). The series of angleplied laminates were of ply orientations $( \pm \theta)_{s}$ where $\theta=0,3,5,10,15,30,45,60,75$ and 90 degrees. specimens were tested with and without notches. The two types of full penetration notches introduced into the specimens were centered silts, 0.25 in. $x$ $0.05 \mathrm{in.}$, and centered circular holes of $0.25 \mathrm{in}$. diameter. All specimens were loaded in uniaxial tension and ultrasonically C-Scanned at specified load increments. The tests were conducted to laminate fracture in order to determine the load-carrying capacity for each angleplied laminate. In conjunction with the experimental program, CODSTRAN analyses were conducted to predict 
fracture for models of the notched and unnotched specimens. Correlations between experimental and analytical results were made, in terms of the pattern and extent of defect growth and load-carrying capacity.

This report contains details on the composite specimen preparation, testing procedures, the RUSCAN experimental facility, analytical methods involving the CODSTRAN computer code, scanning electron microscopy as a verification of failure modes, and comparison of experimental and analytical results.

\section{SPECIMEN PREPARATION}

Individual plies of Fiberite $1034 \mathrm{E}$ prepreg (934 resin matrix with Thornel 300 graphite fibers) were used to prepare four ply panels with a fiber volume ratio of 0.6. A pressing process is used to fabricate the panels. Plies are placed in the press according to desired laminate orientation. Contact pressure is applied while the press temperature is raised to $240^{\circ} \mathrm{F}$. Then $100 \mathrm{ps} 1$ pressure is applied after which the press temperature is elevated to a curing temperature of $350^{\circ} \mathrm{F}$. The panels are cured for two hrs with the 100 psi pressure maintained. Afterwards, the press is cooled to $150^{\circ} \mathrm{F}$ or less before the panels are removed. Each panel fabricated by this procedure is 18 in. long by 12 in. wide by 0.02 in. thick.

From each panel, five 2 in. by $18 \mathrm{in.} \mathrm{specimens} \mathrm{are} \mathrm{cut} \mathrm{using} \mathrm{a} \mathrm{diamond}$ tipped cutting wheel. Two types of full penetration notches, slits and holes, were introduced into the specimens. Slits, centered accurately across the width (tolerance: \pm 0.002 in. from the center line) and roughly along the length are made with an uitrasonic milling machine using abrasive slurry. Dimensions of the slits were $0.25 \mathrm{in}$. by $0.05 \mathrm{in}$. Centered $0.25 \mathrm{in}$. diameter holes were machined using a plated mandrel (core dri11), plated with diamond abrasive. The specimens are sandwiched between pieces of 0.25 in. thick lexan. This is done to ensure against excessive damage occurring to the composite around the edge of the hole. As the mandrel grinds through the lexan and the specimen, debris is flushed away from the tool by a stream of water.

Specimens were tabbed at each end with 2 in. wide beveled aluminum tabs. The surface area of the specimen over which tabs are placed is first abraded with aluminum oxide sand. Excess sand is removed from the surface by a jet of compressed air. Tabs are then clamped to the specimens using an adhesive film. The adhesive film requires a curing period of $2-1 / 2 \mathrm{hrs}$ at $250^{\circ} \mathrm{F}$ to solidly bond the tabs to the specimen. The entire specimen fabrication process is shown pictorially in figure 1 .

\section{TESTING PROCEDURES}

The specimens were loaded in uniaxial tension and concurrently uitrasonically C-Scanned. A $50 \mathrm{kip}$ load frame was used to apply the tensile load to the specimen (fig. 2). Mechanical grips are used to transfer the load to the specimen through the aluminum tabs. The load is incremented in a predetermined step-wise manner with ultrasonic C-Scans taken at each load step. 
The RUSCAN (Real-Time Ultrasonic C-Scan) facility (fig. 3), consists of a microprocessor system, a monitor with full 16 level gray scale reproduction capability, ultrasonic signal conditioning system, and uitrasonic transducers mounted on a two axis (horizontal and vertical) motorized carriage. Water is used as the medium for transmission of the ultrasound signal.

Transducers with an ultrasonic frequency of $10 \mathrm{MHz}$ were used for the thru scan type C-Scan utilized during testing. The transmitter was a $0.50 \mathrm{in}$. diameter focused (at 2 in.) transducer. The receiver was a 0.50 in. diameter flat transducer, positioned as close as possible (approximately 0.0625 in.) to the specimen during scanning. The ultrasonic signal was transmitted from 2 in. away on the opposite side of the specimen.

The ultrasonic signal conditioner and power supply provides excitation to the transmitter and conditions the received signal for optical viewing. A time gating circuit is used to eliminate all undesired portions of the signal (returns due to multiple path deflections). A DC output proportional to the peak signal received in the time gate is sent to the microprocessor where it is digitized and subsequently displayed on the monitor. The output is a 16-level full gray scale image of the digitized ultrasonic signal, with black corresponding to total attenuation (ref. 1).

In addition to data reduction, the microprocessor is used to control the rate and area of scanning. The coordinate limits of a two-axis motorized carriage that determine what portion of the specimen is scanned is controlled by user input. This capability allows areas of interest, such as notches, to be scanned close up. The speed at which the vertical DC motor drive operates is also controlled via user input. The rate of actual data collection is 1 imited by the manner in which the data acquisition software interacts with the system hardware.

As noted previously, the specimens were loaded, step-wise, at a predetermined rate. Each load is held until the desired C-Scan is completed. The loading continues as predetermined until damage, as seen on the gray scale image, dictates a change in the load increment size. Once damage was noted on the 4 ply angleplied laminates, load increments were normally set to 20 lbs, which is the minimum measurable load increase on the load frame. Loading and scanning continue until fracture of the specimen occurs.

The mode of fallure for each specimen was observed and recorded with an AMRAY 1200 scanning electron microscope (SEM). The procedure employed in preparing the fracture surfaces of the specimens is described below.

A segment of the fractured surface located near the tip of the original notch is selected for examination. Having preserved the fracture surface across the entire width of the specimen, the segment, approximately 0.75 in. wide, is cut out using a diamond cutting wheel. It is then mounted on an aluminum seat. The segment is subjected to a sputtering process which coats it with a gold film approximately $200 \AA$ thick. The end result is an increase in electrical conductivity that in turn improves the transmission by the SEM. The fracture surface is examined and photomicrographs revealing the failure mode(s) are taken. 
The Composite Durability Structural Analys is (CODSTRAN) computer code is used to predict progressive fracture of composites (ref. 2). A flow-chart of the program is found in figure 4. Embedded in COOSTRAN is a composite mechanics program known as the Multilayered Fiber Composite Analysis (MFCA) computer code which is described in detali in reference 3.

CODSTRAN is a modular program that does quantitative calculations to predict defect growth and progressive fracture in composite structural components. Capabilities of CODSTRAN include determining the durability of composites with and without defects, determining structural responses due to mechanical and thermal loads, accurate prediction of stress states near defects (stress concentrations), and prediction of ply and laminate level fallure and fracture. The modules comprising CODSTRAN are: (1) the executive module, containing communication links to all other modules; (2) the I/O module; (3) the Analysis module; (4) the Composite Mechanics module (MFCA); and (5) the Fracture Mechanics module.

The Analysis module calls NASTRAN (ref. 4) to calculate both near-field and far-field stresses in a finite element model of the structural component or specimen. The Composite Mechanics (MFCA) module generates laminate proper. ties from constituent properties (composite micromechanics) and uses intraply fallure and interlaminar delamination criteria to check ply and interply fallure, respectively. The Fracture Mechanics module is able to account for both ply level fracture and laminate fracture. The modified distortion energy principle and/or a general quadratic surface fit are used to indicate combined ply level fracture, (ref. 5). Laminate level fracture is based on stress fracture criteria due to inherent flaws.

To predict composite durability, CODSTRAN uses an iterative procedure whereby a load is applied to the finite element mesh of the structure being modeled. The response of the structure to the load can be no damage, damage, or destruction of an element $(s)$. Based upon this response, the load increment is updated as follows: (1) if no damage is predicted, the load is updated by some predetermined load increment; (2) if elements are damaged or destroyed (defect growth or fracture), the same load is re-applied with reduced material properties assigned to the damaged elements. Destroyed elements are purged from the finite element mesh, effectively defining progressive fracture. This load is maintained until equilibrium in the structure is achieved. Equilibrium is defined as the point where the structure, with its modified material properties, can sustain the applied load without the occurrence of further damage. This iterative procedure continues through load increments until fracture of the structure occurs.

\section{EXPERIMENTAL RESULTS}

Results obtained during testing of the 4 ply angleplied graphite/epoxy laminates using the RUSCAN experimental facility are presented here. Fracture tests.were conducted on the following laminates: $[0]_{4},[ \pm 3]_{S},[ \pm 5]_{S},[ \pm 10]_{S}$, $[ \pm 75]_{s},[ \pm 30]_{s},[ \pm 45]_{s},[ \pm 60]_{s},[ \pm 75]_{s}$ and $[90]_{4}$. Ali specimens were $C$-Scanned during loading in order to observe internal damage and defect growth. 
The longitudinal strength $\left(S_{\ell 11 T}\right)$ of the unidirectional composite was $202 \mathrm{ks} i$ determined by using the gross-area stress. This measured value of $S_{\ell 11 T}$ compares favorably with the longitudinal tensile strength, predicted from micromechanics (ref. 3 ), equal to $214 \mathrm{ksi}$. Stress magnitudes at the fracture loads for the series of angleplied laminates are shown in figure 5 .

All specimens were C-Scanned during loading but due to the absence of stress concentrations (because of specimen geometry) very little change or damage was recorded prior to brittle fracture of the composite. Oniy in the $[ \pm 15]_{s}$ laminate where large edge delaminations (15 percent of the specimen width) occurred, starting at 95 percent of the fracture load $\left(P_{f}\right)$, did the C-Scan record composite damage.

\section{NOTCHED SPECIMENS}

Slits. - Specimens with 0.25 in. by 0.05 in. center cracks (slits) were loaded to fracture. The gross area stresses at these fracture loads are presented in figure 5 .

In the very low angle laminates $[0]_{4}$ and $[ \pm 3]_{5}$, the only significant change noted by the $C$-Scan was widening of the crack width due to axial elongation. In the $[ \pm 5]_{s}$ and $[ \pm 10]_{s}$ laminates, significant changes occur around the crack tips. The defects grow in the fiber direction, extending longitudinally to distances up to $14 \times \mathrm{w}$, where $\mathrm{w}=$ initial crack width $(0.05$ in.), away from the crack tip. For the $[ \pm 5]_{s}$ laminate, the damage is first seen at 56 percent of $P_{f}$. Damage is first noticeable at 87 percent of $P_{f}$ in the $[ \pm 10]_{s}$ laminate. No perceptible damage at or near the crack tip occurred during loading of the $[ \pm 75]_{S}$ and $[ \pm 30]_{s}$ laminates. Crack extension first occurred in the $[ \pm 45]_{s}$ laminate at 66 percent of $P_{f}$. At 78 percent of $P_{f}$ the defect growth begins to propagate along the fiber directions. Very large defects emanating from the crack tip and at angles of $\pm 45^{\circ}$ occurred in this laminate prior to the specimen fracture (see fig. 6 ). The $[ \pm 60]_{5}$, $[ \pm 75]_{5}$ and $[90]_{4}$ laminates were tested to fracture without any noticeable damage occurring during loading.

Holes. - To determine what effect different types of notches, in this case slits and holes, have on composite durability and load carrying capacity, the same angleplied laminates were tested with $0.25 \mathrm{in}$. diameter centered holes. The differences in gross-area stresses at loads where laminate fracture occurs are shown in figure 5. It is evident from the results that the load carrying capacity of the graphite/epoxy composite system tested is independent of the notch/defect type. This is in agreement with previously conducted experimental investigations (ref. 6 ).

C-Scan results obtained during loading of the specimens showed significant axial elongation in the unidirectional composite. The longitudinal diameter of the hole just prior to specimen fracture was approximately $1.5 \times d_{0}$ (original diam.). Considerable amounts of defect growth occurred in the low angle, $[ \pm 3]_{s},[ \pm 5]_{s}$ and $[ \pm 70]_{s}$, angleplied laminates above and below the transverse edges of the holes. The damage which occurred was due to shearing which lead to interply delaminations in the directions of fiber orientations as seen in figure 7. Defects in all three laminates first appeared at 70 percent to 80 
percent of $P_{f}$. In addition, edge delaminations occurred in the $[ \pm 10]_{s}$ laminate at 94 percent of $P_{f}$. These delaminations became quite pronounced just prior to specimen fracture. Extensive edge delaminations were also recorded in the $[ \pm 15]_{s}$ laminate starting at 92 percent of $P_{f}$. No detectable damage or defect growth was seen in the remaining laminates of the series during testing. Fracture loads and the percent of $P_{f}$ where damage was first detected by RUSCAN are summarized in table I for both solid and notched specimens.

\section{ANALYTICAL RESULTS}

Using CODSTRAN, cases were run for the series of angleplied laminates with notches (slits and holes) and without notches (solid). The finite element meshes used to model the solid composite specimens and the notched composite specimens are shown in figure 8 together with the laminate material properties used in the finite element analysis. Fallure modes are identified from the combined stress states predicted by the finite element method, with and without consideration of lamination residual stresses. The failure modes can be any of the following: (1) fiber fracture; (2) transply cracking; (3) intraply shearing; (4) longitudinal or transverse compression; and (5) interply delamination. Fracture loads and damage loads (percent of $P_{f}$ where damage was first predicted to occur) as determined by CODSTRAN are given in table $I$.

In the unidirectional and low angle angleplied laminates with slits, CODSTRAN predicts intraply shear failure mode emanating from above and below the crack tips. During successive load iterations, shear failures continue, following the fiber direction longitudinally away from the areas of initial fallure (the crack tip). In these laminates horizontal crack extension occurs as a result of fiber fracture, most commonly occurring near the fracture load $\left(P_{f}\right)$. In the $[ \pm 30]_{s}$ laminate, interply delaminations are predicted to occur at the crack tip at 75 percent of $P_{f}$. At $P_{f}$, intraply shear failure takes place where the delaminations occurred originally, leading to laminate fracture. The same pattern, interply delaminations followed by intraply shear failure is seen in the $[+45]_{s}$ laminate. For the remaining laminates of orientations $[ \pm 60]_{5}$ and $[ \pm 75]_{S}$ the failure mode is transverse tension. No defect growth in these two laminates is predicted to occur as the brittle fracture load is approached.

CODSTRAN results indicate that effects due to lamination residual stresses, caused by the difference between cure temperature during lamination and ambient temperatures at which the specimens are tested, are negligible. Considering residual stresses did not affect defect growth patterns and fallure modes; however, the magnitudes of the loads at which progressive fracture initiated were slightly reduced. In general, for all failure modes, damage onset is more sensitive to the ply strengths than the relatively small residual stresses.

Results of the CODSTRAN analyses of angleplied laminates with centered holes agreed well with experimental results, both indicating that graphite/ epoxy composites are notch-type insensitive. Defect growth patterns and damage mechanisms closely matched CODSTRAN results for the laminates with centered slits. In the low angle laminates, less than $[ \pm] 5]_{s}$ with a centered hole, intraply shear fallures near the hole lead to progressive fracture. Some fiber fracture due to longitudinal tension was predicted. As also typical of behavfor predicted in slitted specimens, damage extended longitudinally (in the fiber directions) emanating from the transverse edges of the hole. In $[ \pm 30]_{S}$ 
and $[ \pm 45]_{s}$ laminates, progressive fracture starting with interply delaminations around the hole, followed by shear fallure was predicted. Brittle fracture was determined by CODSTRAN to occur in laminates of ply angle orientation greater than $[ \pm 60]_{S}$.

Graphical results are presented which aid in explaining the combined stress states and modes of failure in angleplied laminates. Figure 9 shows how graphite fibers in the composite system act as a bridge between points of stress concentration and areas at a distance from that concentration. As shown, a very steep increase in longitudinal stress occurs at the notch tip in the unidirectional composite. In the $[ \pm 45]_{s}$ laminate, the stress concentration is dissipated more gradualiy as the fibers traversing the area from the notch tip outward in the fiber direction, decay the concentration inversely proportional to the square root of the distance from the crack tip. This decay is valid up to a distance of two laminate thicknesses away from the notch tip. For angleplied laminates of higher angle orientations, greater than \pm 30 , the stress concentration is maintained at the crack tip as crack growth occurs, leading to brittle fracture. Shear fallure above and below the notch tips in the angleplied laminates with ply angles less than $\pm 10^{\circ}$ cause progressive fracture. Damage first occurs at or near the notch tip, followed by stress relief, and hence, since the load carrying capacity has been transferred to intact laminate, increased loads can be sustained.

Figure 10 shows load crack-opening-displacement (COD) curves for the unidirectional and $[ \pm 45]_{s}$ laminates. As seen, the COD of the $[+45]_{s}$ laminates is linear until brittie fracture occurs. From zero load up to the load where shear failures start occurring around the notch tip, the COD of the unidirectional composite is also linear. At loads where shear fallures result, there is a discontinuity in the crack opening displacement as progressive fracture ensues. After the composite has stabilized by stress redistribution, the COD will again increase 1 inearly due to higher loads. This type of behavior that the unidirectional composite exhibits is known as defect blunting and is the main contributor to the notch insensitivity of unidirectional composites.

\section{COMPARISON OF EXPERIMENTAL AND ANALYTICAL RESULTS}

Predicted and measured results of laminate strengths, defect growth patterns and fallure modes are presented in this section. Scanning electron microscopy was used to verify both CODSTRAN predicted and RUSCAN observed fallure modes.

\section{LAMINATE STRENGTH}

All CODSTRAN models for the series of angleplied laminates were loaded to laminate fracture in order to determine laminate strengths. Results of both predicted and measured strengths, are shown in figures 11,12 and 13 . The code is conservative in its prediction of strengths in laminates with notches (slits and holes). The average magnitudes of the predicted fracture loads are 69 percent those of the measured loads. Laminate strengths of solid specimens 
were also determined analytically and experimentally. Results indicate that the code is sensitive to the stress concentrations at the crack tip. In composites where stress concentrations are present, the transfer of stresses to surrounding intact laminate will occur if the concentration causes damage to the material. This mechanism of stress redistribution determined by CODSTRAN results in the prediction of lower load-carrying capacities than are measured experimentally.

Both CODSTRAN and RUSCAN results indicate that graphite/epoxy composites are insensitive to notch type. As shown in figure 5, laminate longitudinal strengths are independent of the initial defect type, slit or hole, introduced in the specimen. Accounting for this insensitivity are stress. concentrations of similar magnitudes at the notch edges. The stress magnitudes are equal because of the microscopic heterogeneous nature of the fiber composite material where a notch edge or tip is always blunted by a finite length of exposed fiber regardless of notch type. The stress concentration of magnitude up to the fracture strength ( $\sigma_{f}$ ) exist at the notch tip, but is rapidly dissipated as seen in figure 9 .

\section{DEFECT GROWTH PATTERNS AND FAILURE MODES}

The RUSCAN experimental facility and the CODSTRAN computer code have the capability of monitoring and predicting defect growth in composites, respectively. The shape and extent of damage can be determined as also can the fallure mode( $s)$.

Figure 14 shows a direct comparison between defect growth patterns as predicted analytically and observed experimentally. The results shown are for the $[ \pm 45]_{s}$ laminate with a centered silt where widespread delaminations occurred around the notch tips. These delaminations were predicted by CODSTRAN using the relative rotation fallure criterion, (ref. 3 ). As seen there is excellent correlation for both defect growth patterns and extent.

In the lower angle laminates $[0]_{4}$ to $[ \pm 15]_{5}$, with slits, the dominant mode of fallure is fiber tensile fracture ( $\overline{f i g} .15(a))$. However, photomicrographs reveal some hackles on the fractured surfaces indicating that shear fallures have occurred prior to specimen fracture. This is predicted by CODSTRAN as noted in section 6.0 . In the $[ \pm 30]_{5}$ and $[ \pm 45]_{5}$ laminates delaminations occur around the notch tip followed by intraply shear failures (fig. $15(b)$ ). The delamination progression monitored by RUSCAN corresponds to that predicted by CODSTRAN. A deviation from the predicted shearing type failure is seen on the $[ \pm 30]_{s}$ laminate photomicrographs where there is evidence of ftber fracture. However, numerous hackles seen on the fractured surfaces indicate that shear failure is the primary mode of fallure. For laminates with higher angle orientations, all experimental data indicate brittle fracture caused by matrix transverse fracture and is consistent with the fracture progression pattern predicted by CODSTRAN (fig. 15(c)). Since the combined stress state for these cases is such that equilibrium in the laminate is unattainable after damage onset, CODSTRAN iteratively predicts progressive crack growth and shifting stress concentrations leading to brittle fracture. RUSCAN results, where no damage is detected prior to laminate fracture, indicates brittle fracture does occur in angleplied laminates with ply orientation equal to or greater than $\pm 60^{\circ}$. 
Progressive fracture of angleplied graphite/epoxy laminates is a phenomenon requiring accurate description of complex stress conditions that subsequently cause one or several fallure modes to be present. The analytical and experimental techniques embodied by the CODSTRAN computer code and the RUSCAN facility are well suited to advance understanding and description of progressive fracture in composites. However, the terminology used to describe this complex phenomena must be carefully selected.

During the course of this investigation, it became evident that loose use of terminology inhibited clear understanding and description of progressive fracture of fiber composites. Therefore, it became necessary to use relevant terminology in a specific way in order to succinctiy describe the complex events that were occurring. The following definitions evolved during this study and appear to be appropriate for describing composite progressive fracture. Defect refers to any notch or flaw which is purposely (such as notches) or inadvertently added to the composite during fabrication. Damage is the degradation of mechanical properties in a localized region where failures have occurred. Failure modes, which can be present in composites and have been described, include: a) longitudinal tensile failure including fiber fracture and fiber pullout; b) longitudinal compressive failure characterized by fiber compressive fracture, fiber microbuckling or ply-panel buckling; c) transverse tensile and compressive fallure; d) shear failure including in-plane and intralaminer shearing; and e) interply delaminations. Progressive fracture is described by defect/crack growth in the composite resulting from one or a combination of failure types. Progressive fracture can be blunted if stress equilibrium is recovered or it can continue until fracture occurs. Fracture or laminate fracture refers to the breaking of a structure or specimen into two or more distinct parts.

\section{SUMMARY OF RESULTS}

The significant results obtained by utilizing the CODSTRAN computer code and the RUSCAN experimental facility to study progressive fracture of graphite/ epoxy composite angleplied laminates are summarized below.

(1) The Composite Durability Structural Analysis (CODSTRAN) computer code and the Real-Time Ultrasonic C-SCan (RUSCAN) experimental facility are effective methods of studying progressive fracture of composites.

(2) CODSTRAN gives the investigator an analytical tool for predicting ply combined stress states, failure modes, and fracture propagation patterns.

(3) RUSCAN sensitivity allows accurate monitoring of crack initiation and progressive fracture.

(4) Fracture patterns and crack opening displacements observed via RUSCAN and predicted by CODSTRAN are in good agreement.

(5) Failure modes (fiber fracture, intraply shear, transverse tension and interply delaminations) as predicted by CODSTRAN are verified to be accurate by scanning electron microscopy of fractured specimens.

(6) Angleplied laminate mechanical response, progressive fracture, and fracture load in graphite/epoxy composites is independent of the defect types tested (slits and holes).

(7) In graphite/epoxy angleplied laminates at lower angle laminate orientations (less than $\pm 15^{\circ}$ ) progressive fracture of the composite takes place. 
In laminates of orientation greater than $+60^{\circ}$, brittle fracture occurs. Between these two in the range $\pm 30^{\circ}$ to $\pm 45^{\circ}$, composite fracture is characterized by interply delaminations followed by intraply shear fallure at or near the stress concentration region.

\section{REFERENCES}

1. Kiraly, L. J.; and Meyn, E. H.: Ultrasonic Scanning System for Imaging Flaw Growth in Composites. NASA TM-82799, 1982.

2. Chamis, C. C., and Smith, G. T.: CODSTRAN: Composite Durability Structural Analysis. NASA TM-79070, 1978.

3. Chamis, C. C.: Computer Code for the Analys is of Multilayered Fiber Composites - User's Manual. NASA TN-D-7013, 1971.

4. McCormick, C. W.; ed.: NASTRAN User's Manual (level 15). NASA SP-222 (01), 1972

5. Chamis, C. C.: Fallure Criteria for Filamentary Composites. Composite Materials: Testing and Design, ASTM STP 460, American Society for Testing and Materials, 1969, pp. 336-351.

6. Porter, T. R.: Evaluation of Flawed Composite Structural Components Under Static and Cyclic Loading-Fatigue Life of Graphite-Epoxy Composite Materials. NASA CR-135403, 1979. 
TABLE I. - LAMinATE fRACTURE LOADS $P_{f}$ AND PERCENT OF THE FRACTURE LOAD WHERE INTERNAL COMPOSITE DAMAGE WAS FIRST DETECTED $P_{d}$ FOR FIBER COMPOSITE

ANGLEPLIED LAMINATES WITH AND WITHOUT NOTCHES

\begin{tabular}{|c|c|c|c|c|c|c|c|c|c|c|c|c|}
\hline \multirow{3}{*}{$\begin{array}{l}\text { Ply } \\
\text { orien- } \\
\text { tation }\end{array}$} & \multicolumn{6}{|c|}{ RUSCAN results } & \multicolumn{6}{|c|}{ CODSTRAN results } \\
\hline & \multicolumn{2}{|c|}{$\begin{array}{c}\text { Solid } \\
\text { specimen }\end{array}$} & \multicolumn{2}{|c|}{$\begin{array}{l}\text { Specimen } \\
\text { with } \\
\text { slit }\end{array}$} & \multicolumn{2}{|c|}{$\begin{array}{c}\text { Specimen } \\
\text { with } \\
\text { hole }\end{array}$} & \multicolumn{2}{|c|}{$\begin{array}{c}\text { Solid } \\
\text { specimen }\end{array}$} & \multicolumn{2}{|c|}{$\begin{array}{l}\text { Specimen } \\
\text { with } \\
\text { slit }\end{array}$} & \multicolumn{2}{|c|}{$\begin{array}{l}\text { Specimen } \\
\text { with } \\
\text { hole }\end{array}$} \\
\hline & Pff, & $\begin{array}{l}P_{d}, \\
\text { percent } \\
\text { of } P_{f}\end{array}$ & $P_{f}$, & $\begin{array}{l}P_{d}, \\
\text { percent } \\
\text { of } P_{f}\end{array}$ & $\begin{array}{l}P_{f}, \\
i b\end{array}$ & $\begin{array}{l}P_{d}, \\
\text { percent } \\
\text { of } P_{f} \\
\end{array}$ & Pf & $\begin{array}{c}P_{d}, \\
\text { percent } \\
\text { of } P_{f}\end{array}$ & $\begin{array}{l}P_{f}, \\
i b\end{array}$ & $\begin{array}{c}\mathrm{P}_{d}, \\
\text { percent } \\
\text { of } \mathrm{P}_{f}\end{array}$ & $\begin{array}{l}P_{f}, \\
i b\end{array}$ & $\begin{array}{c}P_{d}, \\
\text { percent } \\
\text { of } P_{f}\end{array}$ \\
\hline$[0]_{4}$ & 8060 & 100 & 7820 & 100 & 6000 & 100 & 8300 & 100 & 4500 & 44 & 4700 & 40 \\
\hline$[ \pm 3]_{\mathrm{S}}$ & 6500 & 100 & 5500 & 100 & 5720 & 79 & 7400 & 100 & 3950 & 50 & 3850 & 40 \\
\hline$[ \pm 5]_{S}$ & 5200 & 100 & 4940 & 56 & 4700 & 69 & 6950 & 100 & 3600 & 50 & 3500 & 40 \\
\hline$[ \pm 10]_{5}$ & 4500 & 100 & 4160 & 87 & 4240 & 77 & 5000 & 100 & 2850 & 75 & 2700 & 40 \\
\hline$[ \pm 15]_{\mathrm{S}}$ & 3700 & 95 & 2750 & 100 & 3300 & 92 & 4400 & 100 & 2250 & 100 & 2150 & 58 \\
\hline$[ \pm 30]_{S}$ & 2620 & 100 & 2150 & 100 & 1750 & 100 & 2150 & 100 & 1000 & 75 & 1100 & 80 \\
\hline$[ \pm 45]_{S}$ & 900 & 100 & 880 & 66 & 950 & 100 & 900 & 100 & 425 & 80 & 425 & 88 \\
\hline$[ \pm 60]_{5}$ & 420 & 100 & 320 & 100 & 360 & 100 & 400 & 100 & 300 & 100 & 200 & 100 \\
\hline$[ \pm 75]_{\mathrm{S}}$ & 220 & 100 & 180 & 100 & 220 & 100 & 200 & 100 & 175 & 100 & 150 & 100 \\
\hline$[90]_{4}$ & 260 & 100 & 180 & 100 & 120 & 100 & 200 & 100 & 150 & 100 & 100 & 100 \\
\hline
\end{tabular}




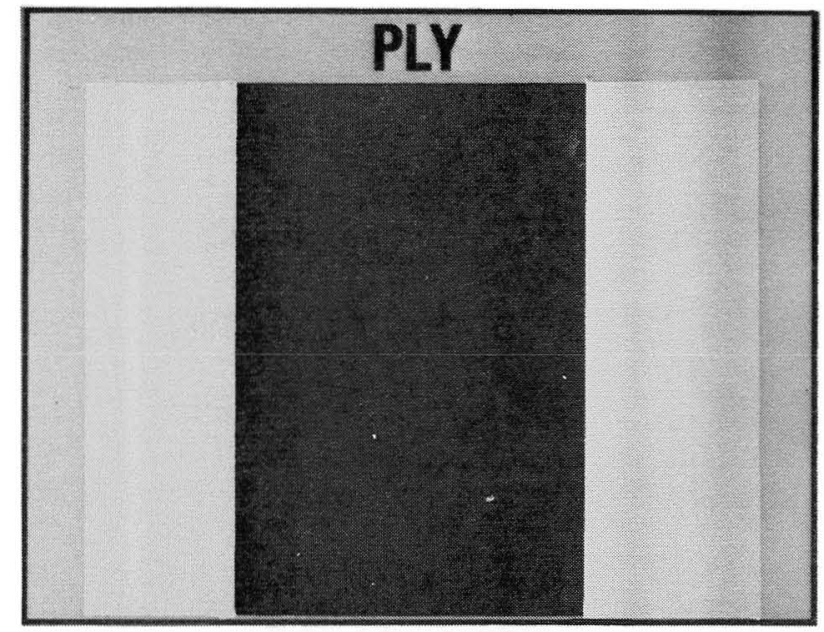

Step 1; Fiberite 934 prepreg; T 300 graphite fiber.

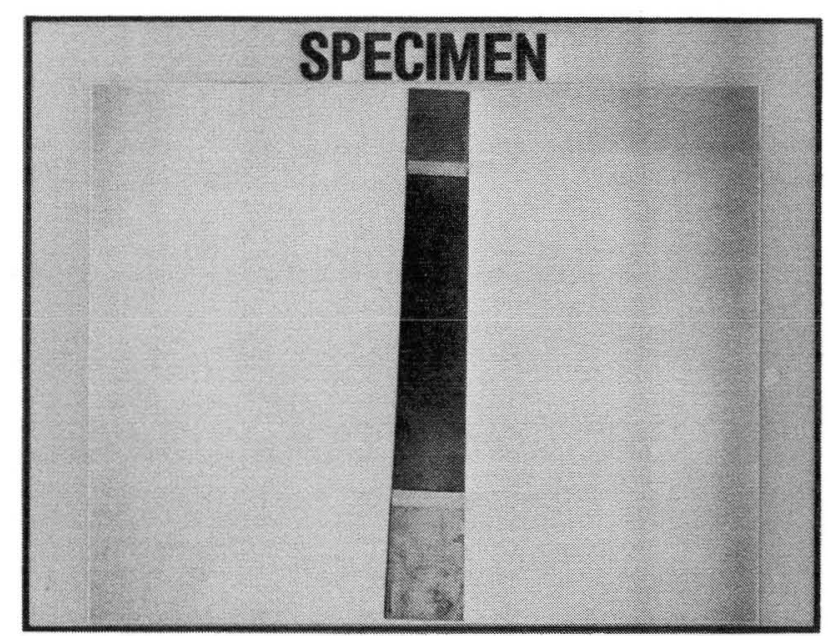

Step 3; specimen dimensions: 18. $\times 2 . \times .02$ inches; machined with diamond tipped cutting wheel; beveled aluminum tabs.

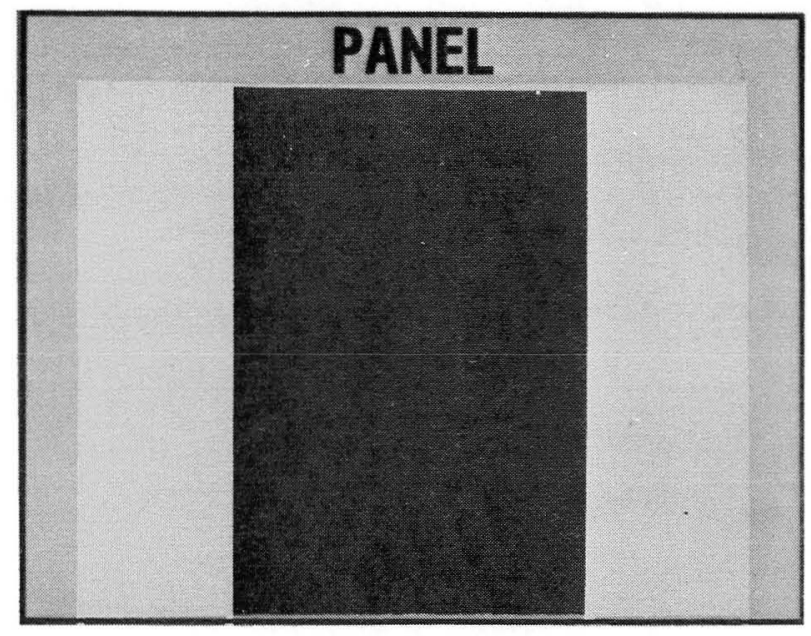

Step 2; 4 plies cured at $350^{\circ}$ for 2.5 hours.

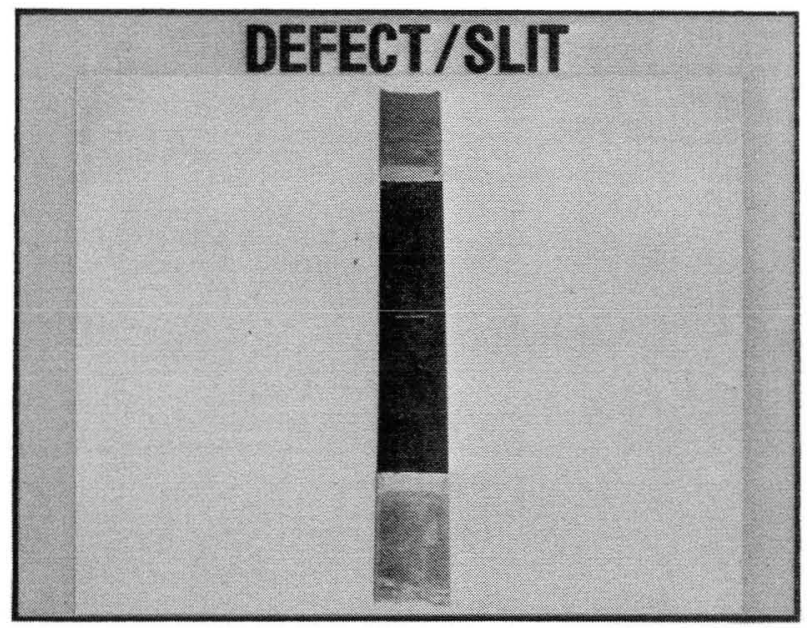

Step 4; slit dimensions: $0.25 \times 0.05$ inches; notching by ultrasonic abrasive slurry.

Figure 1. - Specimen fabrication procedure for graphite/epoxy angleplied laminates with a centered notch (slit). 


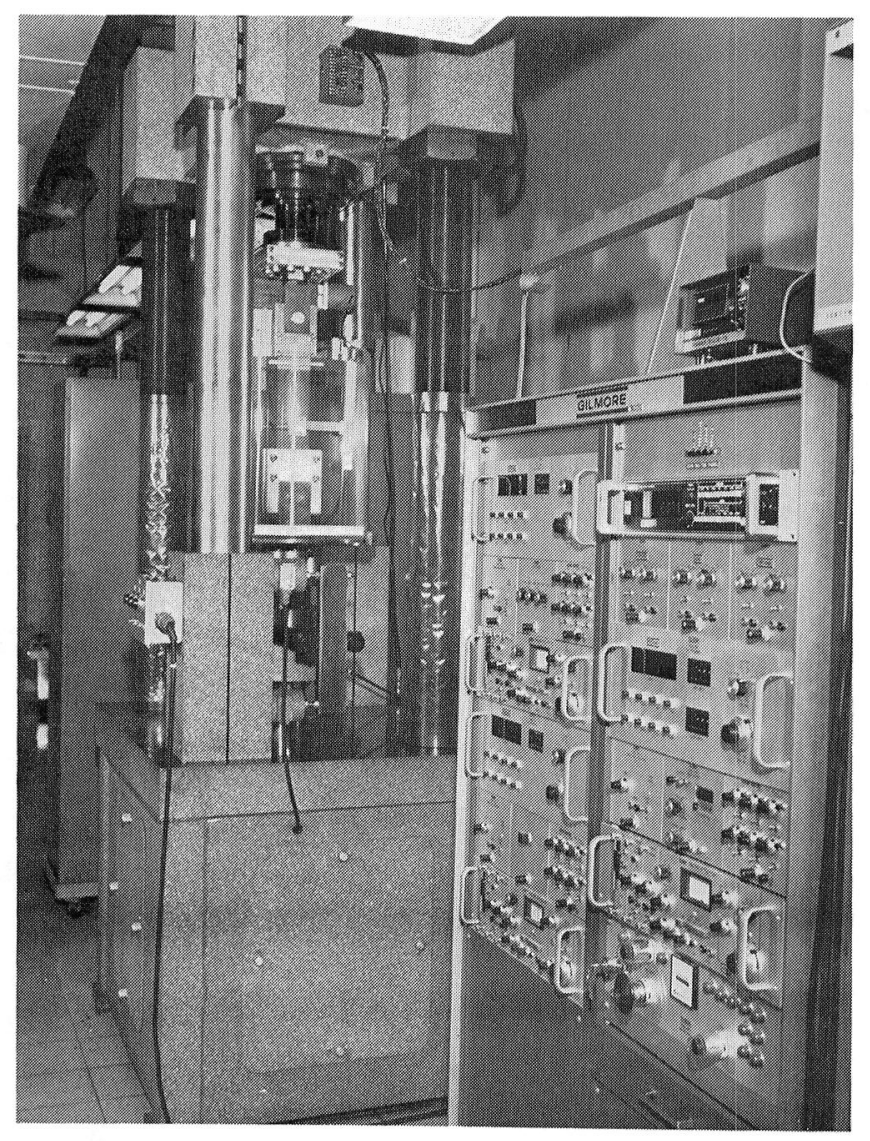

Figure 2. - Load frame used for testing of uniaxial composite tension specimens with ultrasonic transducers mounted on the frame. 

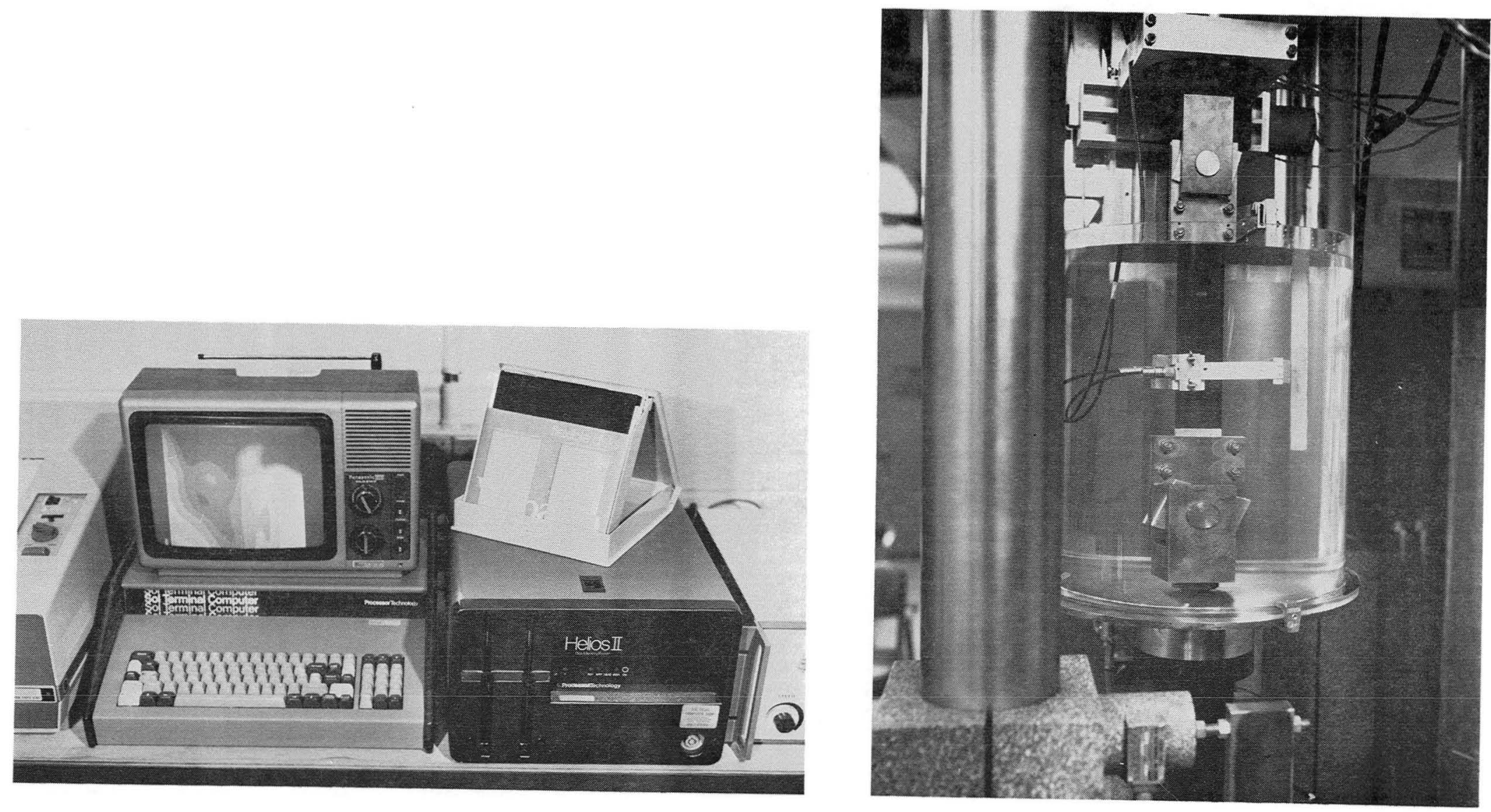
Figure 3. - The Real-Time Ultrasonic C-Scan (RUSCAN) facility. From left, the disk based microcomputer test rig control and data acquisition system, the ultrasonic transducers
in the water bucket (ultrasound medium) with a notched composite specimen in grips on the load frame. 


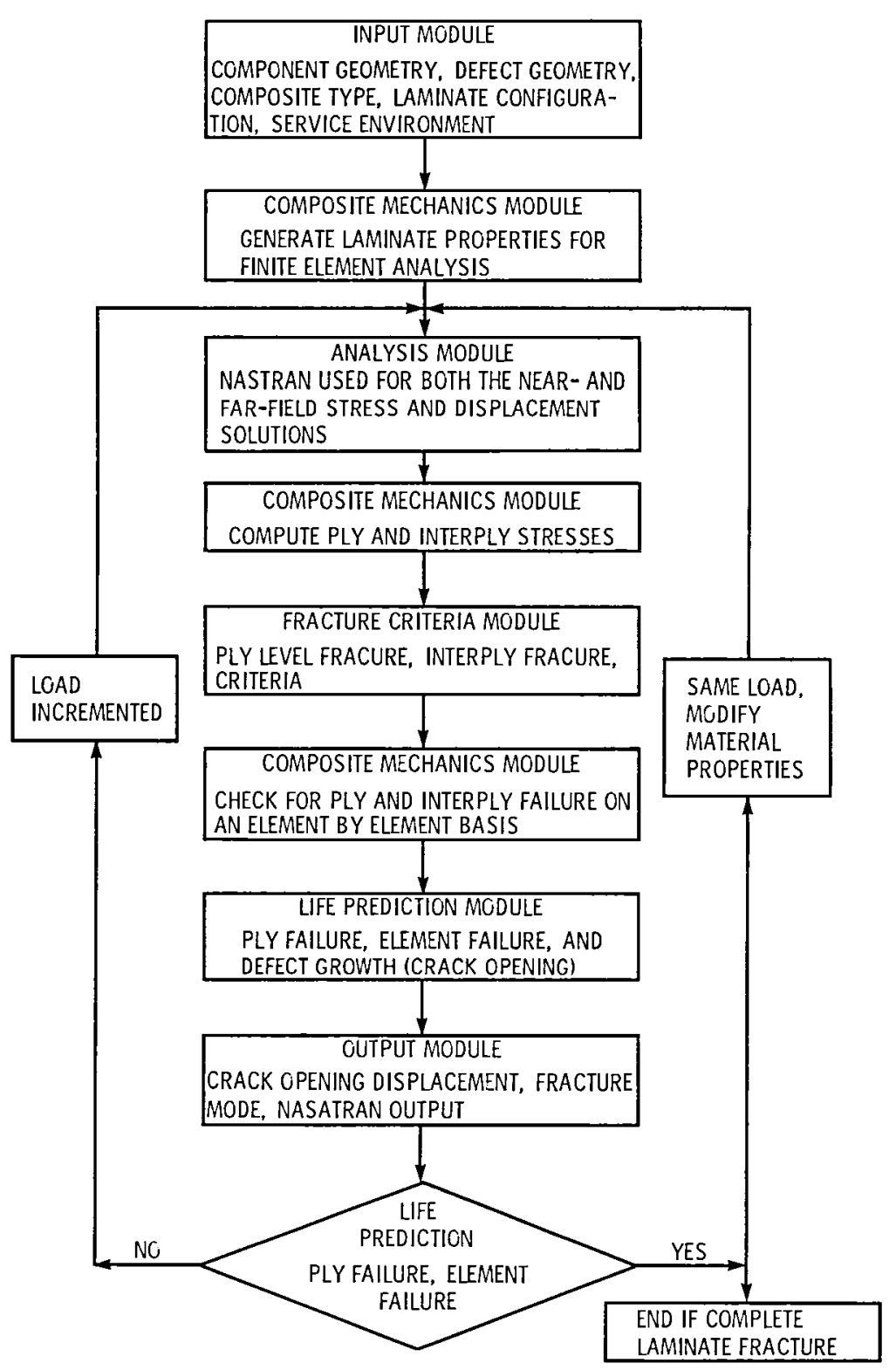

Figure 4. - Flowchart of the CODSTRAN computer code. 


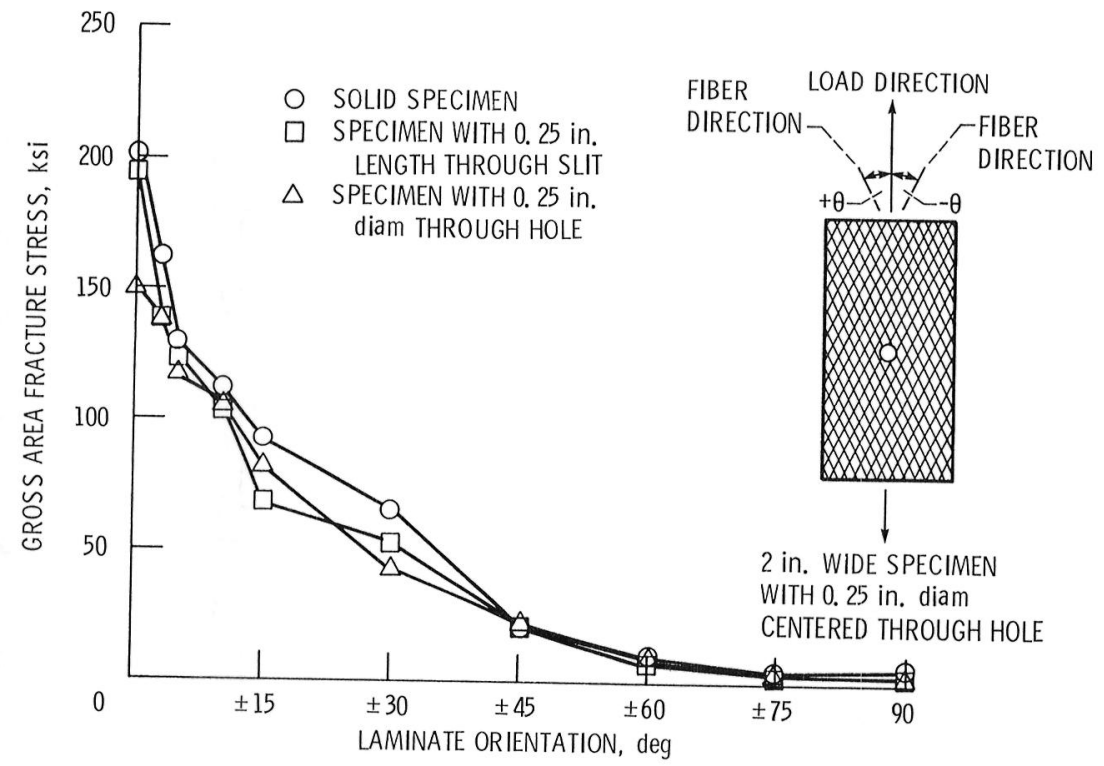

Figure 5. - Angleplied laminate longitudinal strengths.

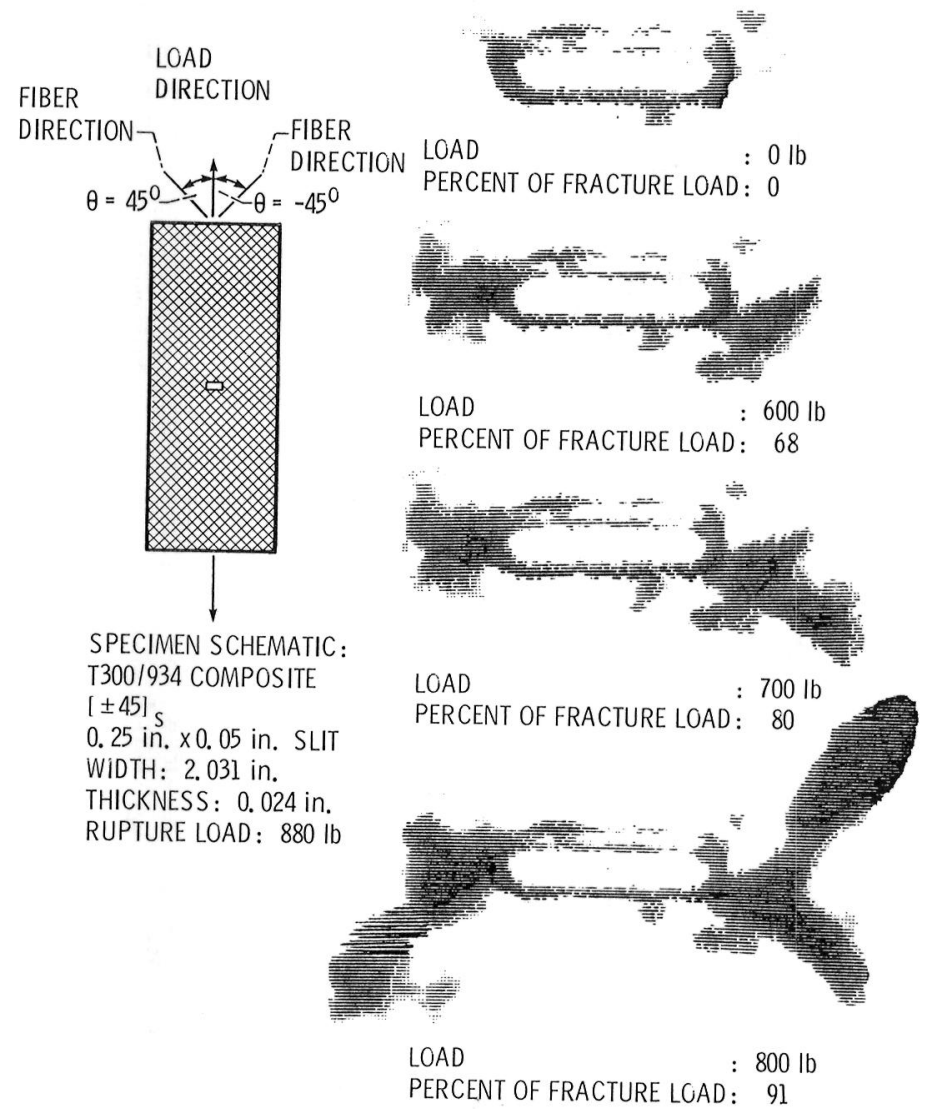

Figure 6. - Defect growth patterns in a $[ \pm 45] \mathrm{S} 4$ ply graphite/epoxy laminate. 

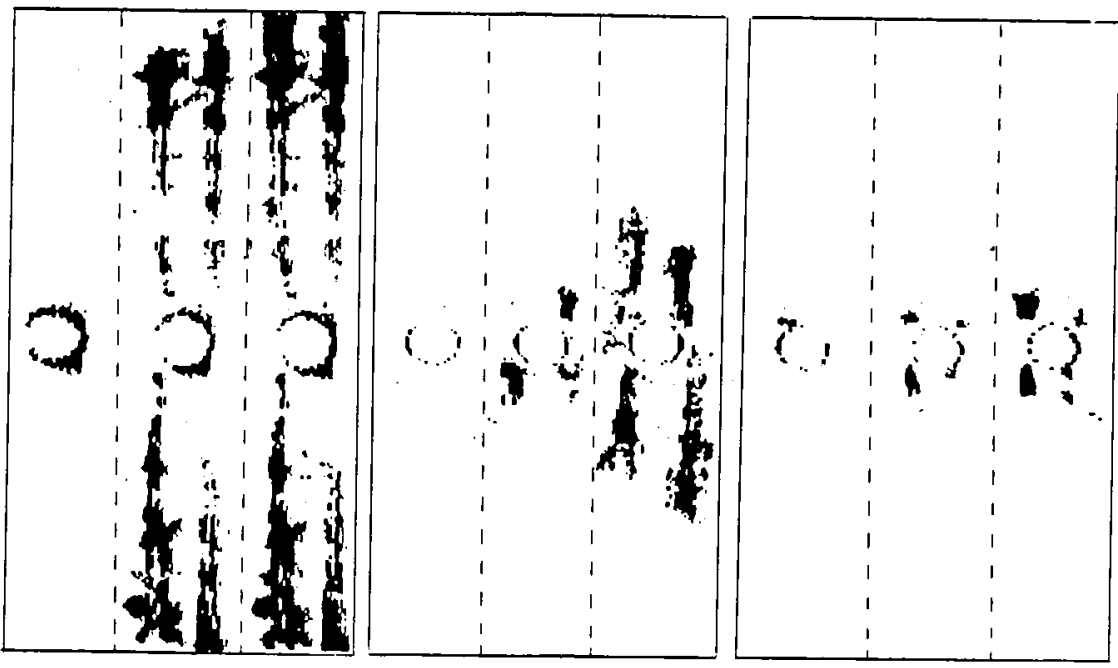

\section{LAMINATE}

ORIENTATION:

LOAD, Ib:

RUPTURE

LOAD, Ib:
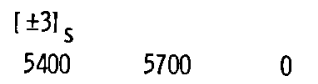

$[ \pm 5]_{5}$

4000

5720

4700

$\begin{array}{ccc}{\left.[ \pm] 0\right|_{s}} & \\ & 4000 & 4200 \\ & 4240\end{array}$
Figure 7. - RUSCAN results showing defect growth in 4 ply graphite /epoxy laminates of orientation $[ \pm 3]_{\mathrm{S}},{ }^{[ \pm 5] \mathrm{s}}$,
and $[ \pm 10]_{\mathrm{S}}$, with a centered $0.25 \mathrm{in}$. diam through hole.
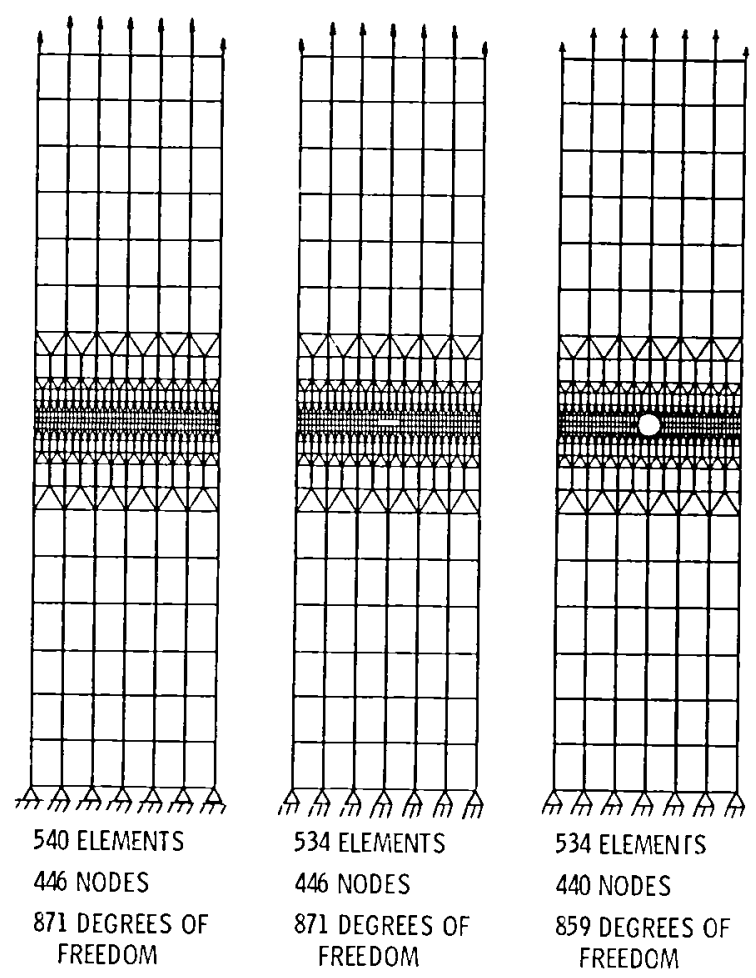

MATERIAL PROPERTIES USED FOR CODSTRAN ANALYSIS*

FIBER VOLUME RATIO, $\mathrm{k}_{\mathrm{f}}$

PLY DENSITY, $p_{\ell}, \mathrm{ID} / \mathrm{in} \mathrm{i}^{3}$

LONGITUDINAL MODULUS, E $E_{\ell l l}$. psi

0.6

TRANSVERSE MODULUS, E

0.057

SHEAR MODULUS, $G_{\ell 12}$, pSi

SHEAR MODULUS, $G_{\ell 23}$, pSi

$1.5(10)^{6}$

POISSON'S RATIO, $v_{\ell 12}$

$0.95(10)^{6}$

$0.37(10)^{6}$

POISSON'S RAIIO, $v_{223}$

0.21

LONGITUDINAL THERMAL EXPANSION

COEFFICIENT, $a_{\ell 11}$, in. $/$ in. $1^{\circ} \mathrm{F}$

TRANSVERSE THERMAL EXPANSION

COEFFICIENT, $a_{\ell 22}$, in. $/ \mathrm{in} .1^{\circ} \mathrm{F}$

LONGITUDINAL TENSILE STRENGTH,

$S_{\ell l 1 T}$, psi

0.47

LONGITUDINAL COMPRESSIVE STRENGTH,

$S_{\text {LIIC. }}$ psi

TRANSVERSE TENSILE STRENGTH,

$S_{\text {Z22T, PSI }}$

$0.33(10)^{-6}$

TRANSVERSE COMPRESSIVE STRENGTH

$0.16(10)^{-4}$

$S_{\ell 22 C}, p s i$

260000

210000

6500

INTRALAMINAR SHEAR STRENGTH,

$S_{\ell 12 S}$, pSi

25000

"PROPERTIES GIVEN ARE FOR A T300/934 GRAPHITE/EPOXY LAMINATE

Figure 8. - Finite element meshes used for the CODSTRAN analyses of the solid composite specinien and the notched composite specimens. 


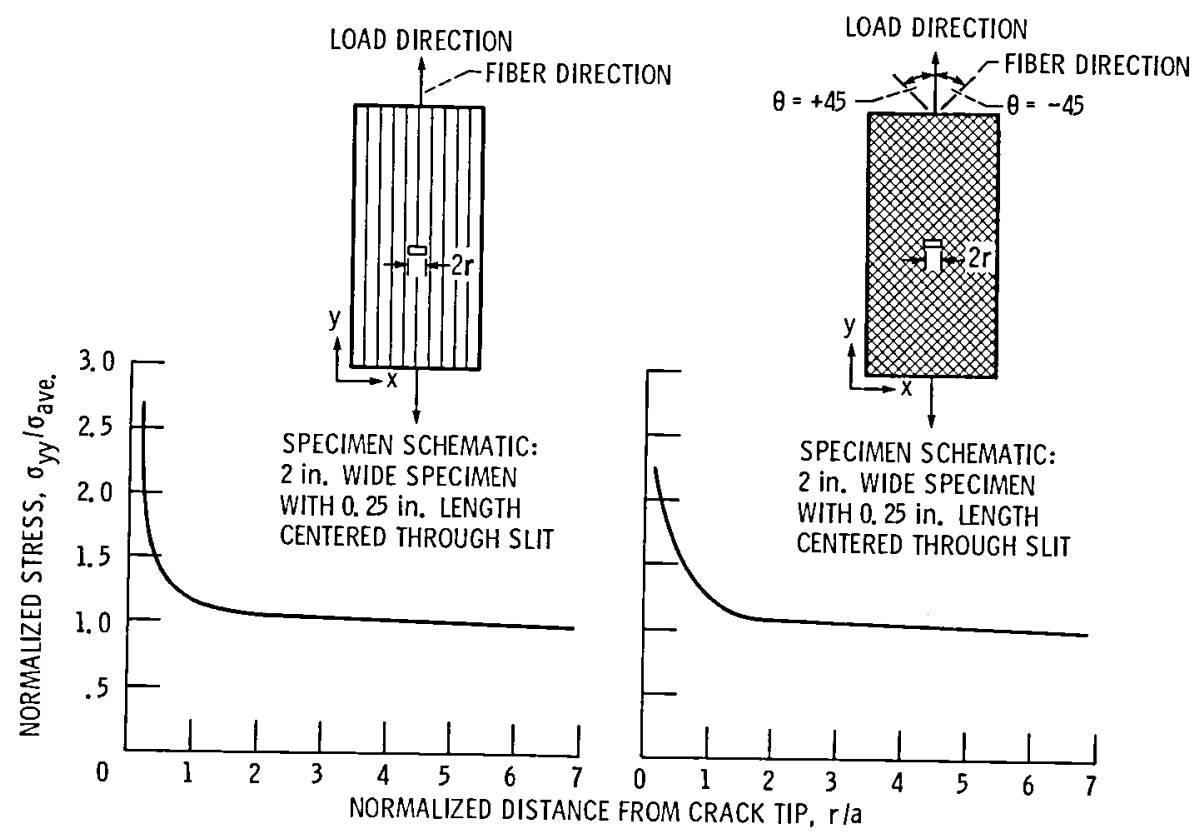

Figure 9. - Crack tip normalized longitudinal stress distribution for the unidirectional and $[ \pm 45]$ s laminates.

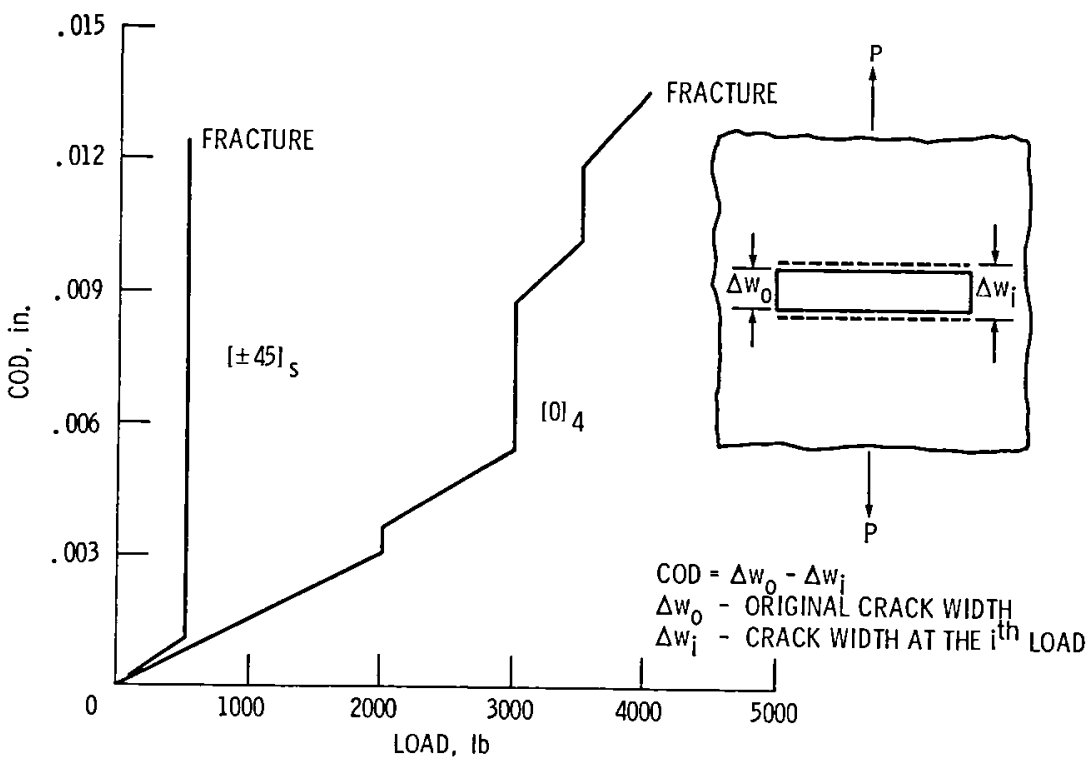

Figure 10. - Crack opening displacement as a function of the applied load in a 4 ply graphite/epoxy angleplied laminate with a centered 0.25 in. through slit. 


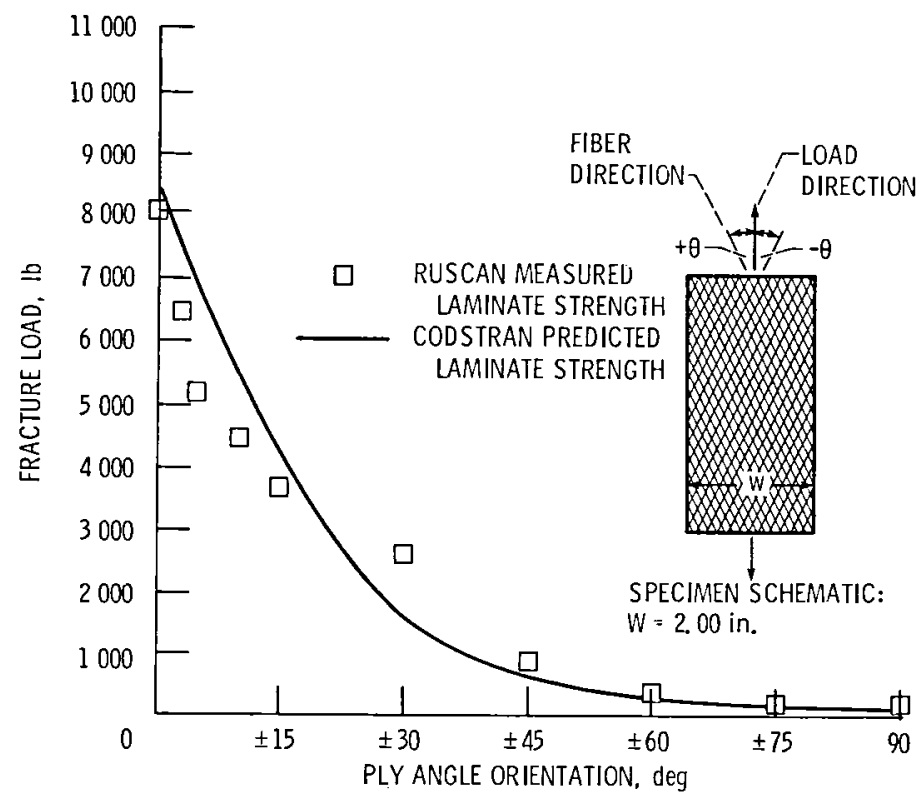

Figure 11. - A comparison of predicted and measured angleplied laminate longitudinal strengths in solid graphite/epoxy composites.

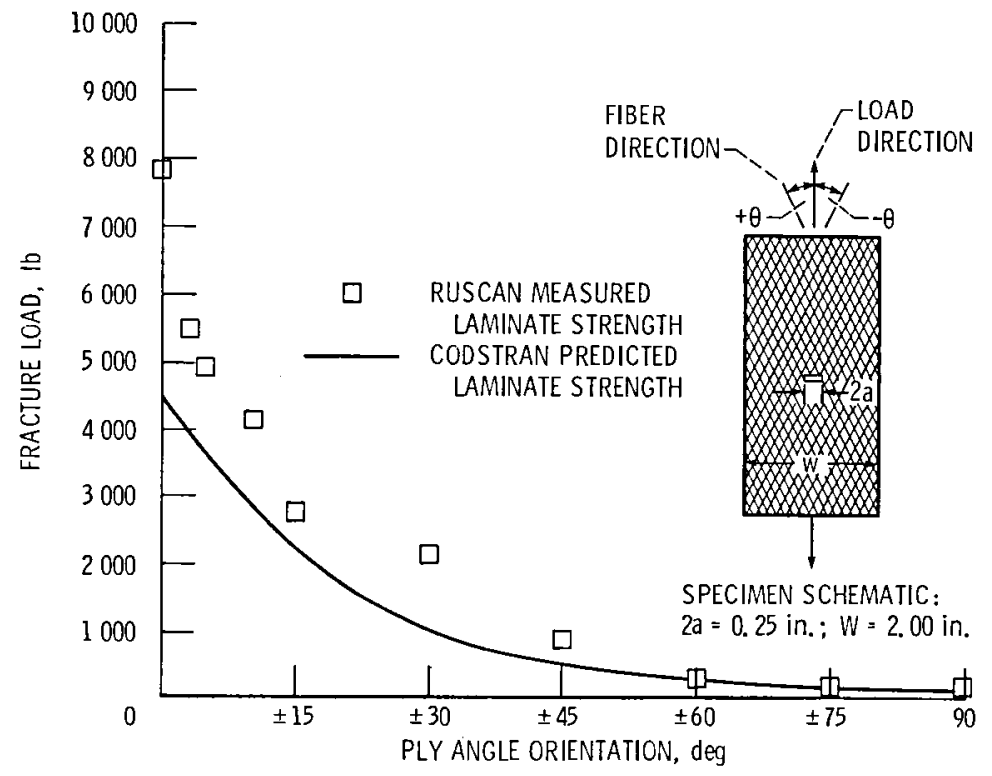

Figure 12. - A comparison of predicted and measured angleplied laminate longitudinal strengths in notched (with slit) graphite/epoxy composites. 


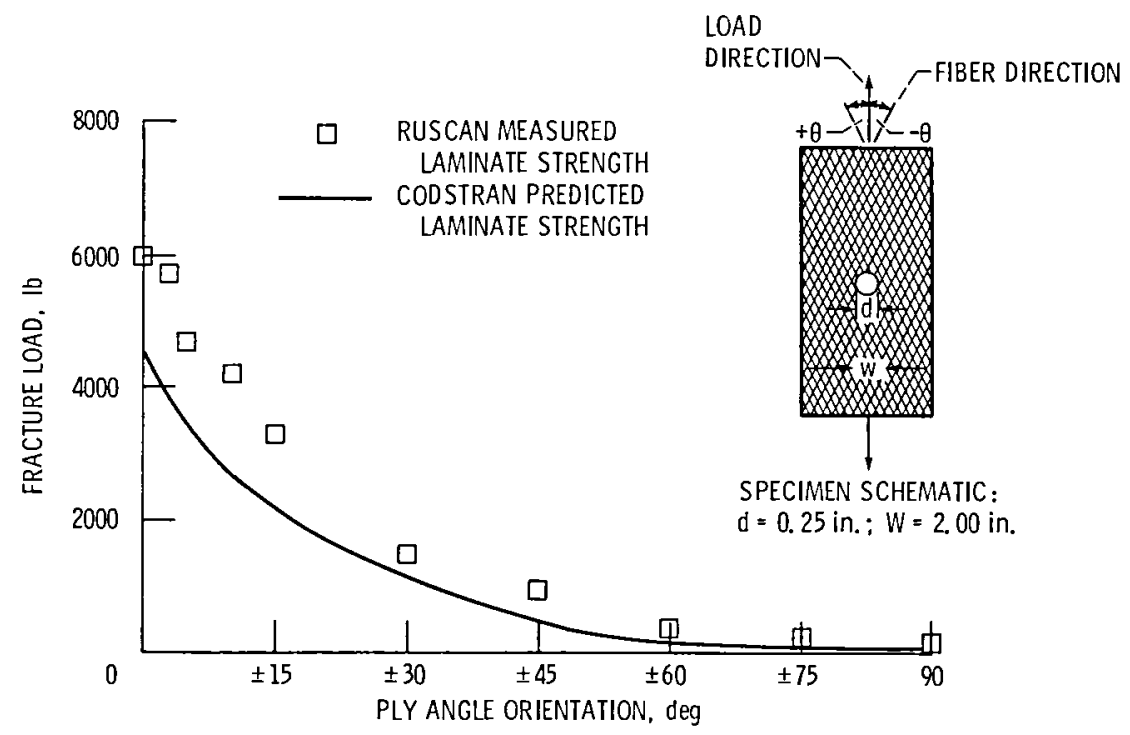

Figure 13. - A comparison of predicted and measured angleplied laminate longitudinal strengths in notched (with hole) graphitelepoxy composites.

CODSTRAN GENERATED RESULTS

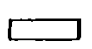

NO LOAD

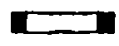

$80 \%$ FRACTURE LOAD (8th ITERATION)

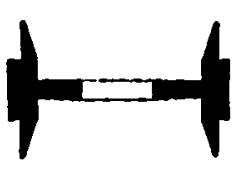

$100 \%$ FRACTURE LOAD (9th ITERATION)

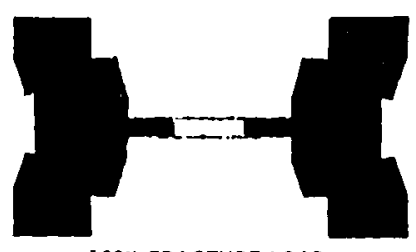

$100 \%$ FRACTURE LOAD (10th ITERATION)

RUSCAN EXPERIMENTAL RESULTS

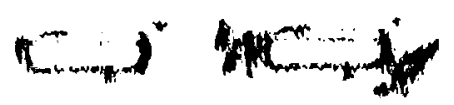

NO LOAD

$$
\text { 80\% FRACTURE LOAD }
$$

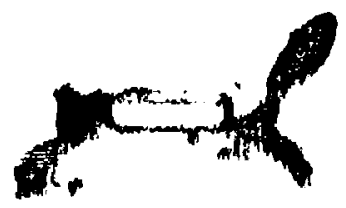

$91 \%$ FRACTURE LOAD

Figure 14. - Progressive fracture of a $[ \pm 45]$ laminate. Results shown are for a 2 in. wide tension specimen with a $0.25 \times 0.05$ in. centered slit. 


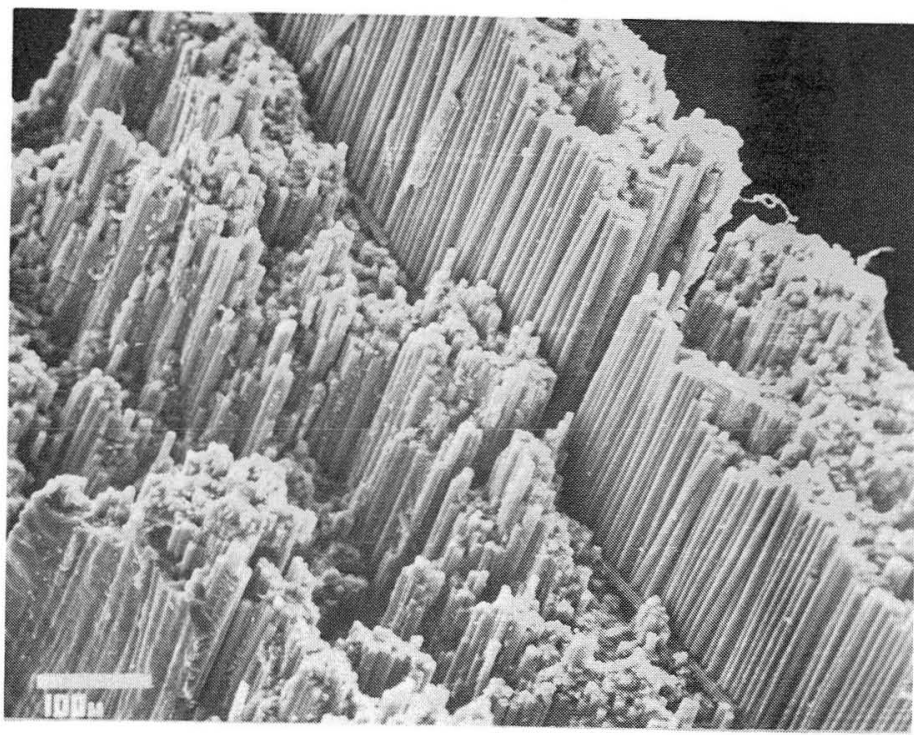

(a) $[0]_{4}-[ \pm 15]_{S}$-- Fiber tensile fracture.

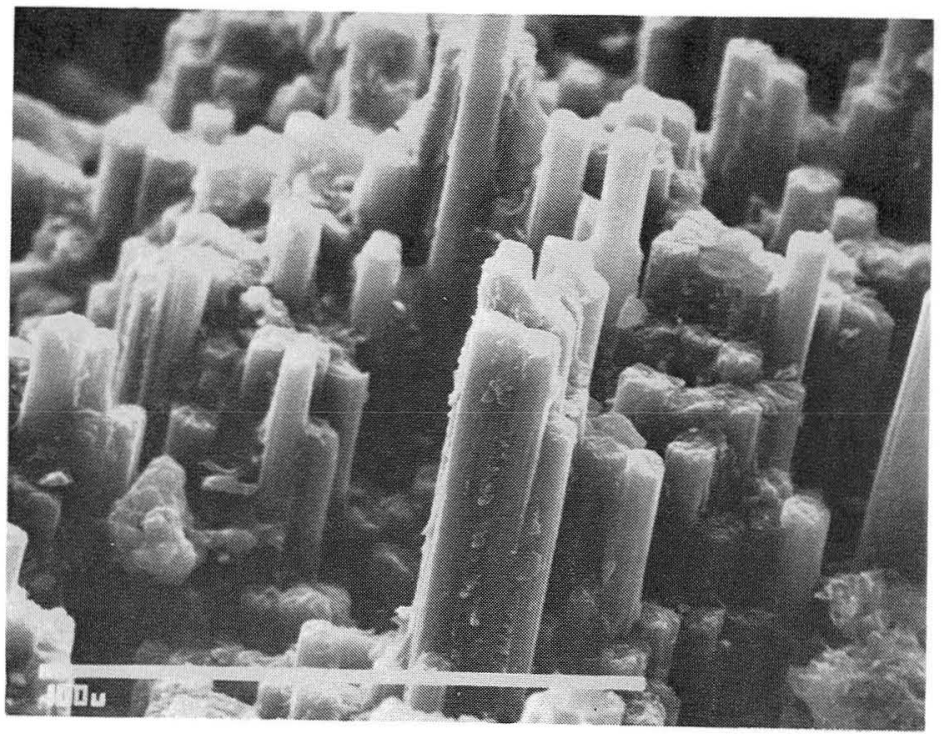

(b) $[ \pm 30]_{S}-[ \pm 45]_{S}--$ Matrix intralaminar/interlaminar fracture.

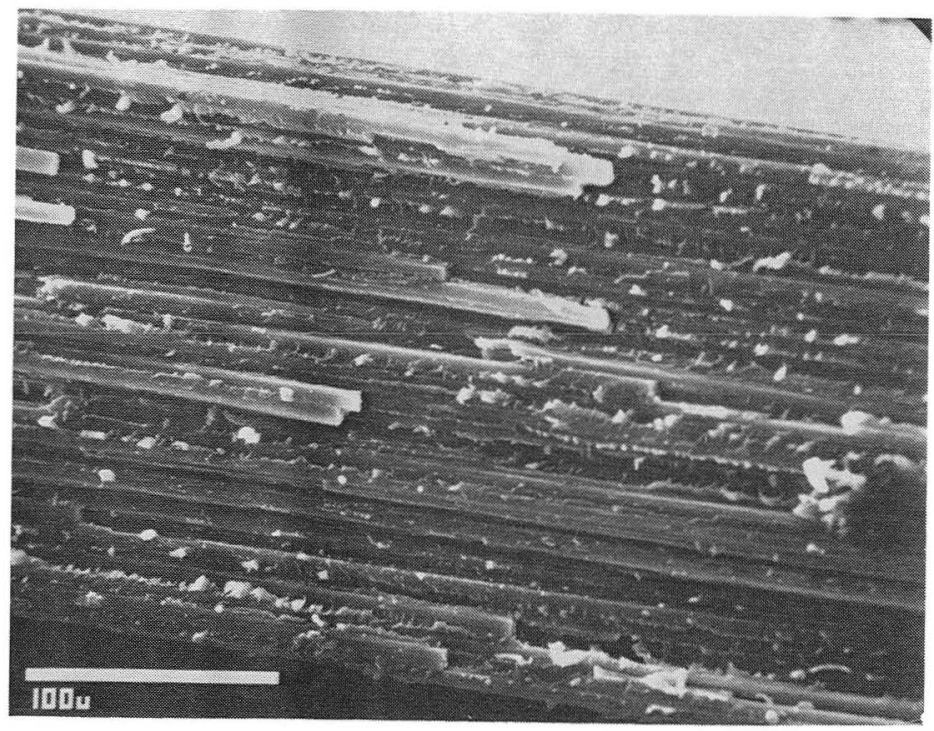

(c) $[ \pm 60]_{5}-[90]_{4}--$ Matrix transverse fracture.

Figure 15. - Photomicrographs revealing fractured surface microstructural characteristics associated with the predicted failure modes. 


\begin{tabular}{|c|c|}
\hline $\begin{array}{l}\text { 1. Report No. } \\
\text { NASA TM-83701 }\end{array}$ & 3. Recipient's Catalog No. \\
\hline 4. Title and Subtitle & 5. Repor Date \\
\hline Progressive Fracture of Fiber Composites & $\begin{array}{l}\text { 6. Performing Organization Code } \\
505-33-5 B\end{array}$ \\
\hline $\begin{array}{l}\text { 7. Author(s) } \\
\text { Thomas B. Irvine and Carol A. Ginty }\end{array}$ & $\begin{array}{l}\text { 8. Performing Organization Report No. } \\
\text { E-2159 } \\
\end{array}$ \\
\hline Thomas B. Irvine and Carol A. Ginty & 10. Work Unit No. \\
\hline \multirow{3}{*}{$\begin{array}{l}\text { 9. Performing Organization Name and Address } \\
\text { National Aeronautics and Space Administration } \\
\text { Lewis Research Center } \\
\text { Cleveland, Ohio } 44135\end{array}$} & \\
\hline & 11. Contract or Grant No. \\
\hline & 13. Type of Report and Period Covered \\
\hline \multirow{2}{*}{$\begin{array}{l}\text { 12. Sponsoring Agency Name and Address } \\
\text { National Aeronautics and Space Administration } \\
\text { Washington, D.C. } 20546\end{array}$} & Technical Memorandum \\
\hline & 14. Sponsoring Agency Code \\
\hline
\end{tabular}

15. Supplementary Notes

Prepared for the Ninth Annual Mechanics of Composites Review sponsored by Air Force Wright Aeronautical Laboratories, Dayton, Ohio, October 24-26, 1983.

16. Abstract

Refined models and procedures are described for determining progressive composite fracture in graphite/epoxy angleplied laminates. Unique Lewis Research Center capabilities are utilized including the Real-Time Ultrasonic C-Scan (RUSCAN) experimental facility and the Composite Durability Structural Analysis (CODSTRAN) computer code. CODSTRAN is used to predict the fracture progression based on composite mechanics, finite element stress analysis, and fracture criteria modules. The RUSCAN facility, CODSTRAN computer code, and scanning electron microscope are used to determine durability and identify failure mechanisms in graphite/epoxy composites. Results indicate that RUSCAN/CODSTRAN is an effective method of studying progressive fracture of composites.

\begin{tabular}{|c|c|c|}
\hline $\begin{array}{l}\text { 17. Koy Words (Sugoested by Author(s)) } \\
\text { Fiber composites; Structural analysis; } \\
\text { Ultrasonic C-Scan; Fajlure mechanisms; } \\
\text { Defect growth; Progressive fracture; } \\
\text { Finite element; Experimental data; } \\
\text { Stress concentrations; CODSTRAN; RUSCAN }\end{array}$ & $\begin{array}{l}\text { 18. Distribution Statement } \\
\text { Unclassified - unlimited } \\
\text { STAR Category } 24\end{array}$ & \\
\hline $\begin{array}{l}\text { 19. Security Classif. (of this report) } \\
\text { Unclassi fied }\end{array}$ & 21. No. of pages & 22. Price ${ }^{\circ}$ \\
\hline
\end{tabular}

•For sale by the National Technical Information Service. Springfield, Virginia 22161 
$\rightarrow \infty$ 
- Narional Aeronautics and Space Administration

Washington, D.C.

20546

Official Business

Penalty for Private Use. $\mathbf{5 3 0 0}$

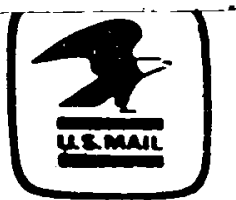

Portege and Fees Paid National Aeronarutics and Sase Administration NASA-451 